\title{
HERBERT MARCUSE E AS "IMAGENS DA LIBERTAÇÃO”
}

\author{
Paulo Irineu Barreto Fernandes*
}

\begin{abstract}
RESUMO
Na década de 1960, os movimentos artísticos de vanguarda e os movimentos estudantis de protesto buscavam, além de uma mudança de comportamento, uma mudança na consciência política dos indivíduos. No entanto, enquanto no campo do conhecimento já se sabia o que deveria ser feito para a transformação social, no campo dos fatos essa possibilidade se via impedida, por isso as exigências revolucionárias conduziram o movimento para fora das universidades, a fim de que a comunidade pudesse realizar materialmente a crítica que surgia no interior da academia. Para Marcuse, a arte poderia contribuir decisivamente para este processo. Ao alertar para uma nova sensibilidade estética, a arte, como manifestação da autonomia e liberdade humanas e não como mero instrumento político, poderia fornecer as "Imagens da Libertação" que, por sua vez, poderiam conduzir a uma nova consciência e à uma nova humanidade.
\end{abstract}

Palavras-chave: Marcuse. Teoria Crítica. Política. Filosofia da Arte.

\begin{abstract}
In the 1960s, the avant-garde artistic movements and student movements of protest, sought a change in the political consciousness of individuals. However, according to Marcuse, while in the field of knowledge already knew what should be done for social transformation in the field of facts that it was not possible. Therefore, the requirements led the revolutionary movement out of the universities so that the community could achieve materially the criticism that arose within the academy, but there are also suppressed. For Marcuse, art could contribute decisively to this process. In a warning to a new aesthetic sensibility, art as a manifestation of human
\end{abstract}

\footnotetext{
* Mestrado em Filosofia pela Universidade Federal de Uberlândia (UFU). Professor de Filosofia do Instituto Federal de Educação, Ciência e Tecnologia do Triângulo Mineiro (IFTM).E-mail: pauloirineu@bol.com.br
} 
autonomy and freedom rather than as mere political tool, can provide the "Images of Liberation", which in turn could lead to a new consciousness and a new humanity.

Keywords: Marcuse. Critical Theory. Politics. Philosophy of Art.

\section{Introdução}

A tolerância com a liberdade de expressão é o caminho do melhoramento, o progresso na estrada da libertação... (MARCUSE, 1970, p. 94).

$\mathrm{Na}$ década de 1960, tanto os movimentos artísticos de vanguarda quanto os movimentos estudantis de protesto buscavam, além de uma mudança de comportamento, uma mudança na consciência política dos indivíduos. Ambas não podiam ser dissociadas, o que levou Herbert Marcuse a escrever, em Um ensaio sobre a libertação:

O desenvolvimento de uma verdadeira consciência continua constituindo a função profissional das universidades. Não admira que a oposição estudantil se defronte com o ódio quase patológico da parte da chamada "comunidade", incluindo amplos setores das organizações de trabalho. No mesmo grau em que a Universidade se torna dependente da boa vontade financeira e política da comunidade e do governo, a luta para uma educação livre e crítica, torna-se uma parte vital da luta mais ampla pela transformação (MARCUSE, 1969, p. 61).

A afirmação acima conduz a dois "caminhos" diferentes, mas não excludentes: de um lado, somos impelidos a investigar o estatuto de uma sociedade que construiu um abismo entre o que é e o que pode (ou deve) ser, abismo este manifesto no distanciamento entre a teoria e a prática, como evidencia a seguinte citação: "A negação do direito à atividade política na Universidade perpetua a separação entre a razão teórica e a razão prática e reduz a eficácia e o alcance da inteligência” (MARCUSE, 1969, p. 62); por outro lado, pode-se afirmar que uma verdadeira contracultura deve apelar 
para a autonomia do sujeito em suas diversas manifestações, o que inclui a arte, como evidencia a seguinte citação: "A obra de arte só pode obter relevância política como obra autônoma. A forma estética é essencial à sua função social" (MARCUSE, 1986, p. 54). Abordar, separadamente, esses dois "caminhos" é o que se busca no presente texto.

\section{A "ponte" entre a teoria e a prática}

Em Um ensaio sobre a libertação, Marcuse afirma que a união entre o que a sociedade pode e deve ser, com o que ela efetivamente é, deve ser preparada dentro da própria teoria. Isso se manifesta como uma "politização externa da Universidade" (MARCUSE, 1969, p. 61), promovida pelos estudantes rebeldes e expressa a lógica interna da educação, que busca traduzir a cultura em realidade, os valores humanos em condições humanas de existência. Enquanto, no campo do conhecimento, já se sabe o que deve ser feito para a transformação social, no campo dos fatos essa possibilidade se vê impedida. Por isso, as exigências educacionais conduzem o movimento para fora das universidades; para as ruas, a fim de que a comunidade tenha que realizar materialmente a crítica que surge no interior da academia, mas que ali também se vê sufocada, impedida de realizar-se.

Para Marcuse, essa recusa da teoria libertadora, dentro da própria academia, repercute como uma negação ao desenvolvimento e amadurecimento da revolta, dentro de (e para) uma sociedade...

- que obriga a grande maioria da população a "ganhar" a sua vida em empregos estúpidos, desumanos e desnecessários,

- que maneja seus prósperos negócios nas costas dos guetos e dos bairros, no colonialismo interno e externo,

- que está imbuída de violência e repressão, enquanto exige obediência e submissão às vítimas dessa mesma violência e dessa mesma repressão,

- que, a fim de sustentar a rendosa produtividade da qual a sua hierarquia depende, utiliza os seus vastos recursos no sentido do desperdício, da destruição, e para a criação cada vez mais metódica de necessidades e satisfações conformistas (MARCUSE, 1969, p. 62). 
A revolta também é moral. Luta contra a hipocrisia de uma sociedade que tornou a sua funcionalidade e a sua prosperidade motivos de vergonha e sofrimento para a maioria dos seus integrantes. A revolta, no entanto, apresenta uma "heterodoxia", uma vez que não se fundamenta na tradicional base de classes, sem deixar de ser uma revolta política, pois possibilita a determinação do alvo e o conhecimento da estratégia para a mudança. Contém em si o seu fim e o seu meio.

A "Nova Esquerda", que opõe uma forte resistência à política tradicional (à política partidária, aos grupos de pressão etc.), criou uma nova classe de mártires. Eles são rebeldes e não visam prioritariamente aos meios, não são mártires na mesma medida em que Sócrates ou Giordano Bruno. O novo mártir visa aos fins, quer vencer e "[...] prefere não ser golpeado, não ir para o cárcere e não perder o seu trabalho" (MARCUSE, 1969, p. 63).

Marcuse alerta para o fato de que a luta pela construção de uma nova sociedadenão pode seguiros passos convencionais. "O processodemocrático organizado por essa estrutura está tão desacreditado que é impossível extrair dele alguma parte que não esteja contaminada" (MARCUSE, 1969, p. 63) e qualquer medida adotada para o desenvolvimento, que não a oposição, "equivale a prolongar indefinidamente a meta de se estabelecer uma sociedade livre" (MARCUSE, 1969, p. 63). Essa impossibilidade abre espaço para as diversas maneiras a partir das quais a revolta pode se manifestar e demonstrar o seu desprezo pelo "espírito de seriedade" da política institucionalizada, como a sátira e a ironia, que se tornam uma dimensão necessária da nova política. Há muito que a classe política fornece material para esse tipo de arte, entre os exemplos, podemos citar o "Provos", na Holanda e o brasileiro "Pasquim".

\footnotetext{
1 A respeito da concepção de Marcuse sobre a Nova Esquerda (New Left), Douglas Kellner escreveu: "Para Marcuse, a Nova Esquerda significa a melhor união entre espontaneidade e organização, combinando forte antiautoritarismo e tendências libertadoras com o desenvolvimento de novas formas de luta política e organização. A Nova Esquerda procurou unir a mudança de consciência com a transformação social, a libertação pessoal com a liberação sociopolítica. [...] Para Marcuse, foi a procura por uma mudança total que notabilizou a Nova Esquerda e a sua valorização da liberdade, da justiça social e da democracia em todas as esferas da existência” (KELLNER, 2005, p. 2).
}

2 Movimento que surgiu em Amsterdã (Holanda), em julho 1965 e existiu até maio de 
Nessas obras e atos, os jovens rebeldes "[...] revivem o riso desesperado e a provocação cínica dos loucos como meios para desmascarar os atos dos sérios que governam o todo" (MARCUSE, 1969, p. 64). A democracia burguesa, em virtude do seu compromisso com as liberdades civis, fornece o terreno propício para a organização dos rebeldes, embora ela mesma se encarregue de dissolver a oposição:

A democracia de massas desenvolvida pelo capitalismo monopolista tem moldado os direitos e as liberdades que concede de acordo com a sua própria imagem e de acordo com os seus interesses; a maioria das pessoas é a maioria dos seus patrões; os desvios são facilmente "contidos"; e o poder centralizado permite tolerar (talvez mesmo defender) o descontentamento radical desde que esse observe as leis e costumes estabelecidos (ainda que se afaste um pouco delas). A oposição é assim absorvida pelo próprio mundo a que se opõe - e pelos próprios mecanismos que permitem o seu desenvolvimento e organização; a oposição sem uma base de massas é frustrada nos seus esforços para obter tal base de massas (MARCUSE, 1969, p. 68).

Assim, defender a democracia equivale a aceitar a estrutura do poder dominante, o que não é suficiente para evitar o conflito entre a luta democrática e as próprias instituições (aparentemente) democráticas. Marcuse (1969, p. 69) denomina "semidemocrático" o processo que trabalha contra a transformação radical, uma vez que o mesmo "produz e sustenta uma maioria popular cuja opinião é originada pelos interesses dominantes do status quo" (MARCUSE, 1969, p. 69).

O que Marcuse (1969) faz é denunciar a existência de um processo semidemocrático no interior da dinâmica do capitalismo. Esse processo mascara as verdadeiras intenções da classe dominante e faz com que a luta pela libertação assuma um caráter antidemocrático e se torne "subversiva".

1967 e é, hoje, considerado um dos precursores da contracultura europeia. O movimento tornou-se mais conhecido pelo episódio das "bicicletas brancas", que eram espalhadas pela cidade de Amsterdã e podiam ser usadas livremente, como uma forma de protesto ecológico, precoce, contra os males causados pelo crescente uso de automóveis, entre outros. Conforme: GUARNACCIA, Mateo. Provos - Amsterdam e o nascimento da contracultura, p. 13. Marcuse cita o "Provos" em Liberation from the Affluent Society, p. 191. 
Essa realidade faz com que o processo de oposição necessite de justificação, pois o sistema (stablishment) garante a falsa noção de liberdade por meio do poder de consumo que atribui àqueles que ele domina.

A necessidade de manutenção do sistema é responsável por uma infinidade de abusos contra a humanidade, como ditaduras militares, genocídios, crimes de guerra, dentre outros. São atos promovidos em nome da liberdade e da democracia e são, na sua maioria, considerados legítimos. $^{3}$

A democracia, no atual estágio da sociedade, cria uma situação ambígua e absurda, pois deve ser defendida, em virtude de garantir uma realidade política que possibilita a transformação. A sua defesa, no entanto, significa a manutenção do status quo. Além disso, cada passo para a transformação radical, como a reivindicada pelos jovens rebeldes, cria um isolamento maior na oposição das massas, provocando uma reação à altura do movimento, por parte dos aparelhos institucionais. Um exemplo apresentado por Marcuse é o de que:

Depois do triunfo eleitoral da reação sobre a esquerda, após a revolta estudantil francesa, o Humanité escreveu (segundo The Los Angeles Times, 25 de junho de 1968): "Cada barricada e cada automóvel queimado deu dezenas de milhares de votos ao partido gaullista" (MARCUSE, 1969, p. 68).

Mas a oposição radical tem que correr esse risco para poder consolidar a sua força e evidenciar o quanto pode custar caro a obediência cega a um regime reacionário e, mesmo a oposição estudantil. Para Marcuse (1969, p. 69), "a mais débil e mais difusa de todas as oposições históricas" cumpriu um papel transformador, como evidencia a seguinte citação:

há boas razões para crer que foram não a opinião parlamentar e as sondagens do Gallup, mas antes os estudantes e a sua resistência que impuseram a mudança de atitude do governo para com a guerra

\footnotetext{
3 Legítimos até o advento da Segunda Guerra Mundial, que proporcionou episódios tão nefastos que a sua justificação tornou-se impossível. Como legitimar a bomba atômica, os campos de concentração e o extermínio de milhões de pessoas?
} 
do Vietnã. E foi a desobediência civil dos estudantes de Paris que despertou a memória reprimida das organizações de trabalho, e fez recordar, por um momento, o poder histórico da greve geral e da ocupação das fábricas, da bandeira vermelha e da Internacional. (MARCUSE, 1969, p. 73).

A alternativa que resta é a racionalização do status quo contra a transformação, o que torna antidemocrática qualquer oposição, cabendo ao radical a culpa, seja por obedecer ou por violar o sistema. Todavia, a ideia de que os sistemas sociais necessitam de oposição para manter a sua própria coesão já estava posta em outros escritos de Marcuse.

As formas prévias de controle social já não bastam em virtude do caráter global e aberto do conflito. Portanto, a mobilização e a reconciliação organizada do povo com a sociedade existente, tomou até agora uma forma de desconhecida eficácia e intensidade. Em primeiro lugar, a sociedade deve ter um inimigo contra o qual se possam mobilizar todas as forças, apartando-as desse modo das potencialidades reais da mesma. E a imagem do adversário se infla e aumenta para que chegue a ser o inimigo total (o comunismo) que ameaça a própria existência da sociedade opulenta. Com esta imagem extremamente dilatada, imposta cotidianamente ao povo, o inimigo proporciona as razões para que se mobilizem todos os recursos existentes em defesa do status quo. Mas, nas sociedades tecnológicas mais avançadas, a citada organização tem lugar de uma maneira que não é terrorista mas democrática e pluralista, e se realiza sobre a base de uma produtividade superabundante que permite à sociedade estender uma melhoria do nível de vida a um maior estrato da população (MARCUSE, 1968, p. 3).

O que fazer, portanto, para se alcançar a tão almejada transformação social, de acordo com Marcuse? O que deve ser feito para que a teoria e a prática se unam? A resposta não é simples e, embora pareça contraditório, Marcuse (1973) defende a ideia de que outra mudança deve preceder a transformação social, a partir do que ele denominou de dialética da libertação: "[...] assim como não pode haver qualquer tradução imediata da teoria em prática, também não pode haver qualquer tradução imediata 
das necessidades e desejos individuais em ações e metas políticas" (MARCUSE, 1973, p. 54), o que significa dizer que nenhuma mudança radical da sociedade dispensa uma mudança na consciência dos indivíduos e também significa que:

[...] a libertação, recusa e renúncia pessoais e particulares devem processar-se dentro do contexto político, definido pela situação em que a oposição radical se encontra, e deve continuar, em teoria e na prática, a crítica radical das instituições vigentes dentro do próprio "Establishment"; por outras palavras, a liberdade (recusa) individual deve incorporar o universal no protesto particular e as imagens e valores de uma futura sociedade livre devem aparecer nas relações pessoais dentro de uma sociedade não-livre (MARCUSE, 1973, p. 54).

O tipo de revolução pretendida por Marcuse é o de uma revolução libertadora, trata-se de uma mudança da consciência dos indivíduos e só pode ser levada a cabo por forças não repressivas, pois a "oposição não pode mudar esse estado de coisas pelos próprios meios que o protegem e o mantém" (MARCUSE, 1969, p. 69). Esta ideia já estava presente no texto $A$ arte como forma da realidade: "Evidentemente, a mera possibilidade de criar semelhante contexto [a união do campo e da cidade; da indústria e da natureza] depende da transformação total da sociedade existente: um novo modo de produção com novos objetivos, um novo tipo de ser humano como produtor [...]" (MARCUSE, 1972, p. 52).

A máxima "os fins justificam os meios" é, como afirmação geral, inadmissível, mas a sua negação também o é, como afirmação geral, pois, na ordem vigente, os que determinam os meios são os mesmos que os executam e esses são definidos de acordo com os fins que interessam à manutenção do status quo.

Um bom exemplo dessa afirmação, para Marcuse, encontra-se na linguagem política, a "armadura do establishment" (MARCUSE, 1969, p. 73), que é o terreno no qual tem início todos os embates. Antes do início de uma guerra, é necessário nomear e classificar o inimigo. "Esta linguagem não apenas define e condena o inimigo, mas também o cria; e esta criação não nos dá o inimigo como ele é realmente, antes como ele devia ser, a fim de cumprir a sua função para o establishment" (MARCUSE, 1969, p. 74). 
Uma vez nomeado o inimigo, os crimes podem ser cometidos, pois este fim justifica os meios e o inimigo merece o castigo. $\mathrm{O}$ inimigo é criminoso e violento, enquanto aqueles que o nomeiam se dizem estrategistas e pacifistas. A guerra, para os últimos, existe em virtude da paz. Para Marcuse, a "guerra" primeiro foi estabelecida no universo linguístico, que só pode ser superado pela ação, pela prática, por isso, ele propõe uma redefinição de termos. Porque os comunistas e os hippies são sujos e a sua rebeldia não é tolerável, enquanto aqueles que bombardeiam e matam são limpos e suas ações são heróicas?

Poderá alguém classificar de agressão o fato de manifestantes perturbarem os trabalhos na Universidade, nos conselhos de administração, nos supermercados, no afluxo do tráfego, quando protestam contra o prejuízo muito mais grave causado na vida de inumeráveis seres humanos pelas forças armadas da lei e da ordem? (MARCUSE, 1969, p. 77).

A proteção do establishment é feita a priori e os pobres, os loucos e os oprimidos são as vítimas do bem-estar social, o que torna ilegítima e ilegal a sociedade existente. Esta não é uma afirmação banal ou irresponsável. Se fosse dado o crédito devido à ela, estaria iniciada a mudança de consciência necessária para a transformação social radical.

Aqueles que aspiram à mudança social devem exigir o reconhecimento público dessa verdade às autoridades, assim como quem cobra o reconhecimento de uma dívida e, ainda, que admita que a mesma não seja paga agora, o seu reconhecimento, por si só, começa a promover a justiça na relação entre credor e devedor.

\section{A autonomia da obra de arte}

Embora a qualidade estética e a atividade política estejam relacionadas em sua natureza, a sua unidade não se dá de forma imediata. Marcuse cita Benjamin que afirmou que "a tendência da obra literária só pode ser politicamente correta se também for correta pelos padrões literários" (BENJAMIN apud MARCUSE, 1986, p. 55). Isso equivale a 
dizer que o uso político da arte (nesse caso específico, a literatura), não pode sacrificar os princípios e valores estéticos e que a forma transcende a tendência política. Se o uso da arte numa cultura afirmativa e burguesa já havia sido condenado desde os primeiros escritos de Marcuse, se a possibilidade de uma arte engajada já havia sido abandonada desde a crítica à estética marxiana e, após os incidentes e as revoltas da década de 1960 , o uso da arte com objetivos marcadamente políticos e de negação, como a música de Dylan e Lennon, também se mostrou ineficaz. A alternativa, de acordo com Marcuse (1986), é concentrar os esforços na autonomia da arte, pois só assim ela poderia colaborar na construção de uma nova sociedade, o que foi observado por Silva, conforme a seguinte citação:

A impossibilidade de resolver este problema [o impasse entre o questionamento do caráter afirmativo da arte burguesa e a condenação da arte engajada] vai levando Marcuse passo a passo para a defesa da posição de autonomia da obra. A arte é autônoma e permanece distinta da revolução, ainda que os movimentos revolucionários nela se inspirem. $O$ único engajamento existente é o do artista com a forma estética (SILVA, 2001, p. 321).

Embora Marcuse, nos seus últimos escritos, não nutrisse mais a mesma confiança no uso político da arte, ele ainda continuava associando a arte à mudança social, o que fica evidenciado na seguinte citação:

Este conhecimento, inexoravelmente expresso na arte, talvez abale a fé no progresso, mas também pode manter viva outra imagem e outro objetivo da práxis, nomeadamente, a reconstrução da sociedade e da natureza sob o princípio do aumento do potencial humano de felicidade e da diminuição do sofrimento. A revolução existe por amor à vida, não à morte. Aqui se situa talvez o mais profundo parentesco entre a arte e a revolução (MARCUSE, 1986, p. 59).

De acordo com Marcuse, há na arte um elemento que não pode ser transposto para a realidade, permanecendo sempre fictício, embora esse elemento possa "antecipar" a realidade. A esperança presente na arte não pode e nem deve, no entanto, permanecer ideal. Esse é o elemento que 
ele denominou de "o oculto imperativo categórico da arte" (MARCUSE, 1986, p. 60). Esse ideal, no entanto, entra na luta apenas com o fim (thelos), transcendendo a práxis concreta, o que conduz o raciocínio de Marcuse ao que pode ser chamado de "dialética entre o caráter afirmativo e o caráter negativo da arte", a partir da qual não seria exagero afirmar que o autor defende que tanto há elementos críticos nas obras de arte marcadamente afirmativas, quanto há elementos conservadores e afirmativos nas obras marcadamente revolucionárias. "A forma estética, em virtude da qual uma obra se opõe à realidade estabelecida é, ao mesmo tempo, uma forma de afirmação através da catarse reconciliadora" (MARCUSE, 1986, p. 61). Essa catarse, na qual impera o aspecto afirmativo, baseia-se nas qualidades da forma artística e na sua ordem não repressiva, evidenciada no fim do sofrimento. A solução, no entanto, preserva algo de irreconciliável e a "dialética" entre os dois polos (afirmação/negação) pode ser evidenciada, de acordo com Marcuse, em casos específicos:

Extrema afirmação: Felizes, vós olhos / que tudo o que vistes, / não importa o quê, / foi um prazer ver. (Fausto de Goethe)

Extrema negação: Oh, maldição! (últimas palavras na última cena da caixa de Pandora, de Wedekind.) (MARCUSE, 1986, p. 61).

No segundo caso, não se pode falar em sublimação e afirmação, pois o grito final é uma imprecação, é uma rebelião contra a "impotente" força do amor.

Para Marcuse (1986), a dialética da afirmação e da negação é a dialética do Belo, que conduz à formação estética e que foi rejeitada pela estética marxiana, devido à dificuldade de se associar esse elemento à arte revolucionária. A estética marxiana acusou a noção de Beleza de elitista e contrária à dura realidade do combate político. Ao mesmo tempo, no entanto, o Belo aparece em movimentos progressistas, como possibilidade de reconstrução estética e material da natureza e da sociedade.

Aqui entram em conflito dois princípios, cuja classificação é oriunda da psicanálise, já abordados por Marcuse em Eros e civilização: $o$ princípio do prazer, pertencente ao domínio do Belo, que é representado por Eros e o princípio de realidade. A revolta é, portanto, contra o princípio de realidade, ao qual o princípio do prazer se opõe. 
Como pertencente ao domínio de Eros, o Belo representa o princípio do prazer. Assim, revolta-se contra o predominante princípio de realidade. Na obra de arte, o Belo fala a linguagem libertadora, invoca as imagens libertadoras da sujeição da morte e da destruição, invoca a vontade de viver. Este é o elemento emancipatório na afirmação estética (MARCUSE, 1986, p. 65). ${ }^{4}$

Há no Belo, de acordo com Marcuse, uma "neutralidade" que, se houver o reconhecimento do que está "oculto", transforma-se em decepção, ou seja, o que é "oculto" sempre parece mais belo e perfeito do que realmente é e a perfeição só pode ser concebida como idealização. Uma vez quebrado o encanto, o que se apresenta é a realidade nua e crua. A imediatidade da apresentação visual, no entanto, impede esse reconhecimento, pois reprime a imaginação.

Marcuse (1986) cita exemplos de representação dos horrores do fascismo possíveis na literatura, devido ao fato de a palavra, nesse caso não apagada pela imagem, conduzir à denúncia. Entre os exemplos, encontram-se escritos de Brecht e Sartres, que proporcionam o que Marcuse denominou de "mímese transformadora" e conduzem ao reconhecimento da realidade do fascismo, nem sempre revelado pela manifestação histórica. "E este reconhecimento é um triunfo: na forma estética (...), o terror é evocado, chamado pelo seu nome, para testemunhar, para se denunciar" (MARCUSE, 1986, p. 66).

O reconhecimento é apenas um momento no interior da consciência, mas, ao ser capturado pela forma estética, é eternizado em sua permanência, não será esquecido, constituirá uma imagem de libertação. Essa realização da mímese contém a qualidade da beleza na sua mais sublime forma: o Eros político, e a obra de arte expressa a sua beleza, na medida em que se opõe

\footnotetext{
4 A banda de rock The Who, no musical Tommy (1975), inspirado em sua "obra prima", a ópera rock Tommy (1969), ilustra bem essa questão, quando o personagem central, ainda garoto, diz, ao chegar à colônia de férias com a mãe, após a morte do pai, na guerra: "Minha colônia será diferente, sempre terá tempo bom. Na colônia do Tommy, as férias durarão para sempre".

5 Brecht: A resistivel ascensão de Arturo Ui e Terror e miséria no Terceiro Reich; Sartre: Os sequestradores de Altona.
} 
à realidade e a substância sensível do Belo é preservada na sublimação estética. "A autonomia da arte e o seu potencial político manifestam-se no poder cognitivo e emancipatório desta sensibilidade" (MARCUSE, 1986, p. 68). Não surpreende, de acordo com Marcuse, o fato de que, historicamente, o ataque à arte autônoma tenha se unido à denúncia da sensibilidade em nome da moral e da religião. Isso deve ter influenciado Friedrich Nietzsche a escrever: "A arte ergue a cabeça, quando a religião afrouxa seu laço" (MAGEE, 2000, p. 173).

Horst Bredekamp (apud MARCUSE, 1986, p. 68-69) afirmou que a luta contra a emancipação da arte do rito religioso tem raízes no ascetismo medieval, para o qual a arte autônoma é tida como sensualidade infame, uma vez que requer a libertação dos estímulos. Essa hostilidade, que gerou episódios como a destruição de pinturas e estátuas na fogueira, não representa, de acordo com Marcuse, apenas a expressão de um fanatismo cegamente violento, mas a consequência de um mesquinho ideal de vida burguês, anti-intelectualista (ADORNO apud MARCUSE, 1986, p. 69), por sua vez, classifica tal hostilidade como um traço do ódio burguês com relação ao sexo.

A mímese, portanto, faz com que a realidade seja traduzida para a memória, retirando o conhecimento do domínio da abstração do conceito, encaminhando-o para o domínio da sensualidade (sensibilidade). "A força sensual do Belo mantém a promessa viva” (MARCUSE, 1986, p. 69).

Enquanto a arte preservar, com a promessa de felicidade, a memória dos objetivos inatingidos, pode entrar, como uma ideia "reguladora", na luta desesperada pela transformação do mundo. Contra todo o feiticismo das forças produtivas, contra a escravização contínua dos indivíduos pelas condições objetivas (que continuam a ser as do domínio), a arte apresenta o objetivo derradeiro de todas as revoluções: a liberdade e a felicidade do indivíduo (MARCUSE, 1986, p. 70).

Assim, a autonomia da arte, de acordo com Marcuse (1986), combaterá a reificação e remeterá a consciência para a possibilidade de uma nova experiência, na qual os seres humanos, a natureza e as coisas não estarão mais totalmente submetidos ao princípio de realidade. A arte 
obedece à lei das transformações e segue lutando pela realização de uma revolução que sempre foi reprimida. Para contribuir para a superação dessa repressão, a arte poderá fornecer as "Imagens da libertação".

\section{As "Imagens da libertação"}

A transformação social pressupõe uma mudança na consciência dos indivíduos, o que, por sua vez, pressupõe uma mudança na organização da estrutura pulsional. Essa mudança pode ter como veículo propulsor a dimensão estética, sobretudo no caráter subversivo e autônomo da arte. Sobre isso, Kangussu escreveu:

O mundo transformado pela sensibilidade estética pode incorporar as faculdades e os desejos humanos de modo que eles aparecem como determinação objetivada da natureza, como "coincidência da causalidade através da natureza e da causalidade através da liberdade" (KANGUSSU, 2008, p. 204).

O mundo transformado pela sensibilidade estética também pode ser entendido como uma nova determinação da realidade, caracterizada pelo encontro entre a natureza e a liberdade. De acordo com Marcuse, é neste momento que a arte (autônoma e subversiva) pode contribuir com a transformação social, fornecendo as imagens de uma nova determinação da realidade. Para ilustrar esta possibilidade, Marcuse escreveu:

O deleite do Belo e o horror da política; Brecht condensou-o em cinco versos:

Dentro de mim há uma luta entre

O deleite de uma cerejeira em flor

E o horror de um discurso de Hitler.

Mas só este último

Me força a escrever.

A imagem da árvore permanece presente no poema que foi "imposto" por um discurso de Hitler. O horror daquilo que é, marca o momento 
da criação, é a origem do poema que celebra a beleza de uma cerejeira em flor. A dimensão política permanece vinculada à outra, a dimensão estética que, por seu turno, adquire valor político (MARCUSE, 1973, p. 115).

O momento teórico que encontramos no pensamento de Marcuse é o que podemos denominar de "concepção final da relação entre arte e revolução", expressa em suas últimas obras, no fim da década de 1960 e ao longo da década de 1970. Tal concepção é marcada pela ideia, plenamente elaborada em $A$ dimensão estética, da autonomia da arte e pela crítica à estética marxista. Não seria demais afirmar, portanto, que, neste momento, a arte já está livre de todos os vínculos e interesses alheios à forma estética, de maneira que ela mesma se constitua no veículo livre de uma liberdade possível. Assim, a arte está liberada para ser: "política", sem ser, necessariamente, política; "cruel", ao denunciar a crueldade do mundo, a partir da forma estética, sem ser, de fato, cruel; "grotesca", ao evidenciar o grotesco, sem ser, necessariamente, grotesca; "sombria", sem ser, realmente, sombria.

No entanto, nem tudo aquilo que se apresenta como expressão artística contrária ao establishment pode ser entendido como uma imagem de libertação. Um exemplo encontra-se no caráter humano do discurso final de $O$ grande ditador, de Charles Chaplin, que coloca a obra numa dimensão muito mais ampla do que aquela para a qual o filme, a princípio, se destina. Se Brecht evidencia o horror do discurso de Hitler, Chaplin faz o mesmo ao negar o discurso do Führer, com o discurso do barbeiro judeu, que havia sido confundido com o ditador.

O célebre filme, no qual Chaplin interpreta o ditador Hynkel, clara alusão a Hitler, e um barbeiro judeu, começa com a provocadora advertência: "Qualquer semelhança entre o ditador Hynkel e o barbeiro judeu é meramente proposital". O barbeiro se vê em problemas com a tropa de choque, até que um oficial alemão, que ele havia libertado na guerra, o reconhece e, por gratidão, impede que os soldados o molestem e aos seus amigos (judeus).

Enquanto isso, Hynkel exerce a sua mitomania na sede do governo, cercado por bajuladores, criados e espelhos, obcecado com a ideia de uma 
raça ariana pura e brincando com o globo terrestre em miniatura, sentindose o imperador do mundo. A cena em que Hynkel brinca com o globo é uma das mais famosas e vistas da história do cinema.

A situação começa a mudar quando o oficial, protetor do barbeiro, não concorda com a postura do ditador e torna-se seu inimigo. Assim recomeçam as hostilidades contra os judeus. $\mathrm{O}$ barbeiro e o comandante são enviados para um campo de concentração. Ao ser confundido com Hynkel, o barbeiro tem a oportunidade de fazer um discurso, em outra cena clássica do cinema, no qual faz um elogio à paz e à fraternidade, em oposição à ideologia (e prática) nazista. Aqui se encontra a principal marca da genialidade de Chaplin que, usando a imagem do ditador, realiza a negação do discurso de Hitler, cuja admirável oralidade sempre foi reconhecida. Poder-se-ia dizer que Chaplin, desta forma, estaria promovendo uma "Imagem da libertação". O discurso pode ser citado numa infinidade de situações diferentes, sem perder a sua força arrasadora.

Considerando que o filme tenha sido produzido em 1940, ou seja, quando as maiores atrocidades cometidas pelo nazi-fascismo ainda não haviam se concretizado, podemos perceber nele uma espécie de alerta da barbárie que estava por vir. O mais certo é que nem mesmo Charles Chaplin tenha julgado que o terror do nazi-fascismo pudesse ir tão longe, o que não impediu que ele fosse mal interpretado nos Estados Unidos da América, país em que vivia, que ainda não estava em guerra. Tal fato fez com ele fosse forçado a se mudar para a Suíça.

Eis os parágrafos finais do discurso de $\mathrm{O}$ grande ditador:

Soldados! Não vos entregueis a esses brutais, que vos desprezam, que vos escravizam, que arregimentam vossas vidas, que ditam os vossos atos, as vossas ideias e os vossos sentimentos. Que vos fazem marchar no mesmo passo, que vos submetem a uma alimentação regrada, que vos tratam como gado humano e que vos utilizam como bucha de canhão. Não sois máquina. Homens é que sois. E com o amor da humanidade em vossas almas. Não odieis. Só odeiam os que não se fazem amar, os que não se fazem amar e os inumanos.

Soldados! Não batalheis pela escravidão. Lutai pela liberdade. No 
décimo sétimo capítulo de São Lucas está escrito que o reino de Deus está dentro do homem - não de um só homem ou grupo de homens, mas de todos os homens. Está em vós. Vós, o povo, tendes o poder - o poder de criar máquinas; o poder de criar felicidade. Vós o povo tendes o poder de tornar esta vida livre e bela, de fazê-la uma aventura maravilhosa. Portanto - em nome da democracia - usemos desse poder, unamo-nos todos nós. Lutemos por um mundo novo, um mundo bom que a todos assegure o ensejo de trabalho, que dê futuro à mocidade $\mathrm{e}$ segurança à velhice.

É pela promessa de tais coisas que desalmados têm subido ao poder. Mas, só mistificam. Não cumprem o que prometem. Jamais cumprirão. Os ditadores liberam-se, porém escravizam o povo. Lutemos agora para libertar o mundo, abater as fronteiras nacionais, dar fim à ganância, ao ódio e à prepotência. Lutemos por um mundo de razão, um mundo em que a ciência e o progresso conduzam à ventura de todos. Soldados, em nome da democracia unamo-nos.

Hannah, estás me ouvindo? Onde te encontrares, levanta os olhos. Vês, Hannah? O sol vai rompendo as nuvens que se dispersam. Estamos saindo das trevas para a luz. Vamos entrando num mundo novo - um mundo melhor, em que os homens estarão acima da cobiça, do ódio e da brutalidade. Ergue os olhos, Hannah. A alma do homem ganhou asas e afinal começa a voar. Voa para o arco-íris, para a luz da esperança. Ergue os olhos, Hannah. Ergue os olhos". ${ }^{6}$

O filme foi um grande sucesso, foi assistido por milhões de pessoas e sabemos hoje que o próprio Hitler o assistiu diversas vezes ${ }^{7}$. Nada

${ }^{6}$ O grande ditador. Direção: Charles Chaplin. Estados Unidos da América: United Artists, 1940 .

7 O documentário The tramp and the dictator, produzido em 2001, trouxe a público um material que contém filmes amadores que mostram, em cores, os bastidores de filmagens de Chaplin. Entre as quais, cenas das filmagens de $O$ grande ditador. O documentário também aborda aspectos importantes da biografia de Chaplin e de Hitler, mostrando curiosas coincidências entre ambos, como, por exemplo, o fato de ambos terem nascido na mesma semana, no mesmo mês e no mesmo ano (1889) e o fato de terem feito a primeira aparição pública de relevância no mesmo ano (1914). Além disso, o documentário deixa claro que Hitler assistiu ao filme $O$ grande ditador mais de uma vez, conforme citação a seguir: 
disso, no entanto, foi suficiente para evitar, ou minimizar, os abusos e as atrocidades que viriam a ser cometidas por Hitler e pelo nazifascismo, o que demonstra que Marcuse tinha razão ao afirmar que:

Nada há de errado em fazer galhofa à custa do "Establishment" - mas há situações em que o divertimento, a troça e o drible perdem todo o sabor, tornam-se insípidos e idiotas, em quaisquer termos, porque são meros testemunhos de impotência política. Sob o fascismo de Hitler, a sátira silenciou: nem mesmo Charlie Chaplin e Karl Kraus conseguiram mantê-la de pé (MARCUSE, 1973, p. 55).

Isso não significa que se esteja minimizando a importância de Chaplin, pois $\mathrm{O}$ grande ditador continua e continuará sendo uma expressão de liberdade que, se não logrou sensibilizar o Führer, ao menos serve para denunciar os seus crimes para a posteridade.

A seguir apresentamos alguns exemplos de "Imagens da libertação", de acordo com Marcuse, pois as mesmas aparecem em momentos diferentes de sua obra.

Em Contra-revolução e revolta, ele as identifica com a obra de Brecht, quando cita o poema "Os amantes", no qual o dramaturgo escreve:

Olha as cegonhas no seu amplo vôo!

Olha as nuvens, dispostas a ficar ao lado delas,

Viajando com elas já quando partiram,

Uma vida para entrar, voando, numa outra vida.

À mesma altura e com a mesma altivez,

Parecem umas ser, meramente, os flancos de outras.

Que a cegonha possa repartir com a nuvem.

A beleza do céu onde brevemente voam,

Que não atardem mais por aqui

E nada vejam senão o oscilar da outra

No vento que ambas sentem agora

Jazendo perto delas, durante o vôo. (...) (MARCUSE, 1973, p. 116).

\footnotetext{
"Neste ínterim, pude consultar o arquivo dos filmes que Hitler tinha pedido para passar: é verdade! Ele pediu 'O grande ditador' e o pediu de novo, no dia seguinte!" Depoimento de Budd Schulberg, roteirista.
} 
Para Marcuse, o voo das cegonhas representa uma "Imagem da libertação", pois revela a capacidade das cegonhas de fugirem da ameaça e remete a consciência do leitor ao "[...] vôo para domínio da liberdade, que é também o domínio da beleza” (MARCUSE, 1973, p. 117).

Em A dimensão estética, ele as visualiza na obra de Georg Büchner:

Ao subir ontem pelo vale acima, vi duas jovens sentadas numa pedra: uma atava o cabelo, a outra ajudava-a; o cabelo dourado caía, o rosto pálido muito sério, e contudo era tão jovem, o vestido preto, e a outra, solícita, querendo ajudar... (...) As jovens levantaram-se, a bela imagem desfez-se; mas, enquanto desciam por entre as rochas, vi desenhar-se outro quadro. Os mais belos quadros, os tons mais cheios reagrupam-se, dissolvem-se. Só uma coisa fica: uma beleza infinita, que passa de uma forma a outra (MARCUSE, 1986, p. 67).

Desde o texto "Algumas considerações sobre Aragon: arte e política na era totalitária”, cuja versão datilografa data de 1945 (MARCUSE, 1999, p. 268), Marcuse já "vislumbrava" ideias que seriam a base de textos redigidos décadas depois, como evidencia a citação a seguir:

A arte, como instrumento de oposição, depende da força alienadora da criação estética: de seu poder em permanecer estranha, antagônica, transcendente à normalidade e, ao mesmo tempo, ser o reservatório das necessidades, faculdades e desejos reprimidos do homem, de permanecer mais real do que a realidade da normalidade (MARCUSE, 1999, p. 270).

Neste texto, Marcuse cita o romance Aurélien, de Aragon, que fala de amor em tempos de guerra e que também poderia ser o prenúncio de uma "Imagem da libertação", pois nele a "[...] ação política é a morte do amor, mas a meta da ação política é a libertação do amor" (MARCUSE, 1999, p. 284). Assim, a arte preserva "sua função política negando seu conteúdo político” (MARCUSE, 1999, p. 286).

No entanto, para além dos exemplos, as "Imagens da libertação" constituem significados que podem, ao longo da obra de Marcuse, ser expressos em três grupos maiores, a saber: 
Imagem 1: "uma nova teoria das pulsões", na qual Marcuse, contrariando alguns pressupostos do pensamento de Kant e de Freud, propõe a libertação a partir da reconciliação entre o princípio de prazer e o princípio de realidade.

Imagem 2: "o caráter emancipatório da arte", no qual Marcuse percebe uma possibilidade de rompimento com o establishment a partir de expressões artísticas tais como a obra de Sthendal e Brecht e em movimentos artísticos revolucionários, como o Surrealismo e a música jovem, nos anos 1960.

Imagem 3: "os movimentos sociais de protesto", nos quais Marcuse aponta para a possibilidade de ruptura com o sistema estabelecido a partir de esforços dos diversos setores marginalizados da sociedade, com ênfase na rebeldia jovem dos anos 1960 .

\section{Considerações finais}

As "Imagens da libertação" contêm, portanto, expressivas mensagens políticas, artísticas e libidinais. Joan Alway, em Critical Theory and Political Possibilities, sintetizou bem esse conjunto de expressões ao afirmar:

Para Marcuse, a necessidade vital da revolução incorpora necessidades e sensibilidades estético-eróticas, que podem guiar para muitas formas diferentes de política radical. Que ele não reconheça e desenvolva mais completamente sua compreensão destas formas, é uma consequência de seu avanço na busca pelo sujeito revolucionário (ALWAY, 1995, p. 97).

Todas estas manifestações artísticas apresentam uma liberdade e uma atemporalidade que as capacita a expressar, de alguma forma, a liberdade da qual elas mesmas gozam. E a arte, por estar desvinculada de qualquer uso predominantemente político, se posiciona para "além do bem e do mal".

A liberdade e a autonomia da arte, porém, também pressupõem a liberdade e a autonomia da recepção. O sujeito, que interpreta a sociedade, 
deve se colocar numa posição tal que o capacite a conceber a arte e a realidade de uma nova maneira, o que nos conduz a uma dialética entre a arte e o sujeito, ou entre a forma estética e a recepção, na qual o artista assume o papel de mediador. A arte modifica o indivíduo e vice-versa e, ao modificá-lo, modifica a sociedade. Só assim é possível, livremente, entender a Nona sinfonia, de Beethoven; Guernica, de Picasso; o teatro de Brecht ou a música de Bob Dylan como representantes da arte que não deve pagar tributo a nenhuma outra determinação política ou social. São obras de arte, nada mais! Se orientam a consciência dos homens para uma nova sensibilidade, se elevam o espírito ou denunciam o "caos", o fazem sem perder a sua autonomia, evidenciando, assim, a exequibilidade de um novo indivíduo e de uma nova sociedade.

Se a humanidade foi capaz de produzir imagens de ódio e de destruição, entre as quais se destacam a imagem da bomba atômica, lançada sobre Hiroshima no fim da Segunda Guerra Mundial e, no século atual, a imagem da destruição das torres gêmeas, em Nova Iorque, no fatídico dia 11 de setembro de 2001, também pode e deve produzir imagens de libertação tão expressivas. Afinal, o que são as imagens? Para Aristóteles, elas são como as coisas sensíveis, só lhes faltam a matéria. Para Marcuse (1999), podem ser o prenúncio de uma nova consciência, de uma nova sensibilidade e de uma nova humanidade.

\section{Referências}

ALWAY, Joan. Critical Theory and Political Possibilities. London: Greenwood Press. 1995.

GUARNACCIA, Matteo. Provos - Amsterdam e o nascimento da contracultura. Tradução de Roberta Barni. São Paulo: Conrad Livros, 2001. FERNANDES, Paulo I. B. Imagens da Libertação: a relação entre práxis política, transformação social e arte na Teoria Crítica de Herbert Marcuse, 2009. 100 f. Dissertação (Mestrado em Filosofia) - Faculdade de Artes, Filosofia e Ciências Sociais, Universidade Federal de Uberlândia, Uberlândia, 2009. 
KELLNER, Douglas. Radical Politics, Marcuse, and the New Left. In: MARCUSE, Hebert. The New Left and the 1960s: Collected Papers of Hebert Marcuse. Editado por Douglas Kellner. New York: Routledge, 2005, p. 2-30.

. Herbert Marcuse and the Crisis of Marxism. Berkeley: University of California Press, 1984.

MAGEE, Brian. História da filosofia. Tradução de Marcos Bagno. São Paulo: Edições Loyola, 2000.

MARCUSE, Herbert. Tolerância repressiva. In: .; WOLF, R. P. Crítica da tolerância pura. Tradução de Ruy Jungmann. Rio de Jnaeiro: Zahar Editores, 1970.

. A dimensão estética. Tradução de Maria Elisabete Costa. Lisboa: Edições 70, 1986.

totalitária. In:

Algumas considerações sobre Aragon: arte e política na era Kellner. Tradução de Maria Cristina Vidal Borba. São Paulo: Fundação Editora da UNESP, 1999. p. 269-288.

. An Essay on Liberation. Boston: Bacon Press, 1969.

. Contra-revolução e revolta. Tradução de Álvaro Cabral. Rio de Janeiro: Zahar, 1973.

. El arte como forma de la realidad. Tradução para o castelhano de José Fernández Vega. Publicado originalmente como Art as Form of Reality. Original em Inglês, em New Left Review, n. 74, jul./ago. 1972, p. 51-58. Disponível em: <http://www.marcuse.org/herbert/pubs/70spubs/727tr04 ArteRealidad.htm>. Acesso em: 20 fev. 2009.

. Eros e civilização. 8. ed. Tradução de Álvaro Cabral. Rio de Janeiro: Guanabara \& Koogan, 1981.

. Liberdade e agressão na sociedade tecnológica. Tradução de Anamaria de Vasconcelos. Revista Civilização Brasileira, Rio de Janeiro, v. 18, p. 03-12, mar./ abr. 1968.

PLATÃO. As Leis - Epinomis. Tradução de Edson Bini. São Paulo: Edipro, 1999. 
REVISTA SELECÕES DO READER'S DIGEST. Rio de Janeiro: Editora Ypiranga, Tomo LIII, n. 316 e 317, maio de 1968.

REVISTA VEJA. São Paulo: Editora Abril, n. 01, 11 de setembro de 1968. Disponível em: <http://veja.abril.com.br/acervodigital/home.aspx>. Acesso em: 20 fev. 2009.

SILVA, Rafael C. Notas sobre esclarecimento e arte contemporânea em Marcuse e Adorno. In: DUARTE, R.; FIGUEIREDO, V. (Org.). Mímesis e Expressão. Belo Horizonte: Editora UFMG, 2001. p. 315-326.

Data de registro: $28 / 10 / 2010$

Data de aceite: $23 / 03 / 2011$ 
